\title{
The Unified Scientometric Model. Fractality and transfractality
}

\author{
R. BAILÓN-MORENO, ${ }^{\mathrm{a}}$ E. JURADO-AlAMEDA, ${ }^{\mathrm{a}}$ R. RUIZ-BAÑOS, ${ }^{\mathrm{b}}$ \\ J. P. COURTIAL ${ }^{\mathrm{C}}$ \\ a Departamento de Ingeniería Química. Facultad de Ciencias, Universidad de Granada, Granada (Spain) \\ b Departamento de Biblioteconomía y Documentación, Facultad de Biblioteconomía y Documentación, \\ Universidad de Granada, Granada (Spain) \\ ${ }^{\mathrm{c}}$ Laboratoire de Psychologie - Education - Cognition Développement (LabECD), \\ Université de Nantes, Nantes (France)
}

\begin{abstract}
A Unified Scientometric Model has been developed on the basis of seven principles: the actornetwork principle, the translation principle, the spatial principle, the quantativity principle, the composition principle, the centre-periphery or nucleation principle, and the unified principle of cumulative advantages. The paradigm of the fractal model has been expanded by introducing the concept of fractality index and transfractality. In this work, as the first demonstration of the power of the model proposed, all the bibliometric laws known and all their mathematical expressions are deduced, both the structural distributions (Zipf, Bradford and Lotka) as well as the Price's Law of the exponential growth of science and Brookes' and Avramescu's Laws of ageing.
\end{abstract}

\section{Introduction}

Scientometrics is based on a set of empirical laws of two types: bibliometric distributions (Zipf, Lotka, and Bradford), of structural character; and dynamic growth and ageing laws (Price, Brookes, and Avramescu). Science can be studied from three approaches: non-relational activity indicators, first-generation indicators or co-citation analysis, and second-generation relational indicators or co-word analysis.

Behind Scientometrics lie various models. Historically, the oldest models are the Mandelbrot's fractal model and the principle of cumulative advantages or the principle of "success breeds success". The former refers to the structure of science, which is assimilated to self-similar structures such as those that also appear in other social and natural settings. Fractality involves a geometry that is generated by chaotic phenomena (chaos theory, butterfly effect) and complex phenomena (complexity theory). On the other hand, the latter does not refer to structures but rather reflects a generally accepted

Received June 28, 2004

Address for correspondence:

RAFAEL BAILÓN-MORENO

Departamento de Ingeniería Química. Facultad de Ciencias, Campus de Fuentenueva

Universidad de Granada, 18701-Granada, Spain

E-mail: bailonm@ugr.es

0138-9130/US\$20.00

Copyright (C) 2005 Akadémiai Kiadó, Budapest

All rights reserved 
concept that prior accumulation helps confer subsequent advantage against competitors (Matthew effect or advantage of the elite and the Ortega Hypothesis or advantage of the mediocre). Also the widely accepted Kuhn Model posits that science goes through periods of revolution in which new paradigms are created, and these alternate with periods in which science follows established paradigms.

With the advent of the relational approach, the Actor-Network Theory and Translation Theory are the models that reveal the structure of science and its dynamics. These scientific networks and their translation can be manifested fundamentally by coword analysis.

Scientometrics is based on several theories for which a unifying model is needed. Recently, such a unifying model was developed in a doctoral thesis. The present paper, the second in a series of five articles, presents the theoretic underpinnings for the model proposed. ${ }^{1}$

\section{Objectives}

The objective is to develop a Unified Scientometric Model. This will be based on a set of principles derived from established theories and laws but combined in a completely novel way. The model should unify all known and accepted bibliometric and scientometric laws: Zipf's Law in its various forms (Condon-Zipf, BoothFederowicz, Brookes-Zipf and Zipf-Mandelbrot) ${ }^{2-9}$ Bradford's Law in its various forms (Nuclei of Bradford, Brookes-Bradford Equation, Leimkuhler Equation) ${ }^{2,10-22}$ Lotka's Law and Pareto's Law, ${ }^{15,23-31}$ in addition to exponential growth law of science ${ }^{27 ; 32-35}$ as well as Brookes' and Avramescu's ageing laws. ${ }^{34,36-49}$ Furthermore, it should offer new equations that fit the empirical values better than do previous expressions. More compelling, it must generate new laws (not yet described in the literature) related to the structure of scientific networks and their dynamics.

\section{Principles of the Unified Scientometric Model}

\section{First Principle: Actor-Network Principle}

Science and Technology (Technoscience) are comprised of networks of actors according to the Actor-Network Theory of Callon and Courtial. ${ }^{50-73}$

This principle implies:

a) Those entities that create and modify Technoscience are called actors.

b) Actors can be defined by words taken not as linguistic or meaning units but only as verbal or scriptural productions in associated to action, in other words like a kind of elemental action (verbal definition).

* or Estoup-Zipf 
c) Actors can be defined according to their relative position in the network (strategic definition).

d) Actors can be human or non-human (researchers, laboratories, countries, scientific journals, research topics, documents, measuring devices, financing, etc.). No distinction is made between them, as all are equally necessary to construct Technoscience.

e) Technoscience is comprised of a network of interconnected actors.

f) A network is not homogeneous, but rather have areas of greater interconnection, called interest centres. The interest centres are actors.

\section{Second Principle: Translation Principle}

The dynamics of the technoscientific networks are governed by Latour's Translation Theory. ${ }^{55,58-60,64-66,74-78}$

This principle implies, among other matters, the following:

a) The verbal definition of the actors evolves over time by the imposition of positive and negative modalities (linguistic meaning of the translation).

b) The position of the actors within the network and their strategic situation also change with time (geometric meaning of the translation).

c) Translations involves the equilibrium between natural and social interactions and stabilization of the actors. Translations depend on the particular or collective interests of the actors, on their strategic advantage, and on their intrinsic strength.

\section{Third Principle: Spatial Principle}

The translation implies the existence of a space, with temporal and geometric components of the Hausdorff-Besicovitch type, the spatial dimensions of which are fractionary. $5,8,9,79-84$

As opposed to the Mandelbrot model, the conditions of fractality, are not necessarily imposed, although they may be in a particular case.

\section{Fourth Principle: Principle of Translation Quantitativity}

According to Ruiz-Baños et al., translation, $T$, is equal to the variation in the qualities of the actors, $Q$, measured as a quantity according to how they move in the translation space. ${ }^{65,66}$

That is, the translation resembles the derivate or gradient of the quality function with respect to the coordinates of the translation space: 


$$
T(x)=\frac{d Q(x)}{d x}
$$

where $x$ is a spatial coordinate (geometric or temporal). As the geometric coordinate, the range, $r$, can be chosen and, as the temporal coordinate, time or age, $t$.

The fourth principle implies fundamentally two types of situations:

a) Translation by changing the strategic position:

$$
T(r)=\frac{d Q(r)}{d r}
$$

b) Translation by temporal evolution:

$$
T(t)=\frac{d Q(t)}{d t}
$$

\section{Fifth Principle: Principle of Translation Composition}

Any translation, complex though it may be, can be considered the composition of associated elemental translations in a series, in parallel or in combination with the translations. ${ }^{65}$

This principle is analogous to the principle of composition of movements of Galileo or to the mechanisms of chemical reactions.

\section{Sixth Principle: Centre-Periphery Principle or Nucleation Principle}

The translation space is the field generated by a point, which can be called a centre or nucleus, which all the actors seek to approach in order to improve their strategic position.

The concept of centre implies the existence of a periphery according to the model of Hongzhou-Guohua and Jiménez-Contreras and that of nucleation, the existence of a nucleus, and successive Bradford zones. ${ }^{17,85,86}$.

In combination with the Spatial Principle established above, it is deduced that:

a) With geometric coordinates, the space is a line, circle, sphere, or hypersphere (according to whether the dimension is 1,2,3, or more), or forms of fractionary dimensions thereof, depending on the complexity of the network of actors.

b) With temporal coordinates, when the dimension $=1$, all actors evolve along a single temporal line; when the dimension $>1$ the actors evolve along multiple temporal lines. 


\section{Seventh Principle: Unified Principle of Cumulative Advantages}

The translation, $T$, is proportional to the product of the strategic advantage, $s$, (function of the spatial, geometric, or temporal coordinates), by the intrinsic advantage, $q$, (quantitative variable function of the qualities or attributes of the actor or actors).

Mathematically, the above can be defined by the following expression, which we shall call the Fundamental Equation of the Unified Scientometric Model:

$$
T=k s q
$$

where $k$ is the proportionality constant related to the dimension of the translation space, $s$ is the strategic advantage, and $q$ is the intrinsic advantage.

In other words, an actor (or group of actors) has a greater translation capacity depending on intrinsic capabilities as well as a more or less advantageous position within the network.

\section{The Unified Scientometric Model for Monotonous Translations}

We define monotonous translations as those in which an actor (or group of actors), $F$, transforms into another actor or group of actors $G$ in an irreversible process as they move in the same direction through the translation space. In these monotonous translations, translations are strictly increasing or strictly decreasing:

$$
F \stackrel{k}{\longrightarrow} G
$$

The following examples are provided for clarity:

1. If we arrange the terms or words that linguistically define, for example, a network of scientific documents according to their decreasing frequency of appearance, an increase in the range necessarily implies decreased frequency (trivial deduction because by definition they have been arranged in descending order). In this case, our model must generate Zipf's Law in all its fractal versions: Condon-Zipf, Booth and Federowicz, Zipf-Brookes, and Zipf-Mandelbrot, as well as an alternative equation for the samples that deficiently fit the above expressions (cases that we shall call "unified").

2. If we arrange the researchers by their scientific production in descending order, an increase in the range necessarily implies a decrease in production. Similarly, this could be applied to the case of production by journal, research centre, or country. From the model, we should be able to infer the following fractal laws equivalent to Zipf's Law: Lotka's Law, Pareto's 
Law, and Bradford's Law in their different versions (Brookes, Leimkuhler, etc.). Furthermore, the model should give rise to alternative equations for samples of deficient fits to the above laws ("unified" cases).

3. As example 2, the model should be applicable to the case of arranging links in the network according to their strength (determined for example by the equivalency index of the co-word analysis) or to the arrangement of the research topics according to their density, their centrality, or the number of documents by theme, by author, by journal, etc. Until now, few if any, specific laws have been established for these examples.

4. In the case of temporal coordinates, the model should lead to the Price's Law of Exponential Growth of Science or Brookes' Ageing Law.

The equation of the model for Monotonous Translations was deduced in the following way:

If the translation is the disappearance of $F$ to be transformed into $G$, the translation function, according to the fourth principle, is expressed by the following expression:

$$
T(x)=\frac{d F(x)}{d x}
$$

where $F(x)$ is the value of the $F$ quality dependent on the $x$ coordinate.

The quality $F(x)$ can be the frequency of a word in a text, the production of a journal, or the references of a given age that appear in a group of documents. The $x$ coordinate can be either a range or a time period.

Let us assume that the strategic advantage, $s$, corresponds to the following expression consisting of a reworking of Mandelbrot's principle of the accumulated advantages: ${ }^{8}$

$$
s=-\frac{1}{(x+m)^{\varphi}}
$$

where $m$ is the Mandelbrot parameter which will hereafter be called the Mandelbrot Distance, since it represents the geometric or temporal distance for the first actor to the centre of the translation space (for this, $m$ is added to $x$ so that the distance refers exactly to the centre when the first actor is not positioned exactly at that point). The exponent $\varphi$ will hereafter be called the fractality index (for reasons disclosed below).

Let us assume now that the intrinsic advantage, $q$, is equal to the value of quality (expressed, logically, by quantity):

$$
q=F(x)
$$


Therefore, the fundamental equation of the model for irreversible translations is:

$$
\frac{d F(x)}{d x}=-k \frac{F(x)}{(x+m)^{\varphi}}
$$

This is a ordinary differential equation with variables separable:

$$
\frac{d F(x)}{F(x)}=-k \frac{d x}{(x+m)^{\varphi}}
$$

Integrating from $x=1$ to $x$ :

$$
\int_{F(1)}^{F(x)} \frac{d F(x)}{F(x)}=-k \int_{1}^{x} \frac{d x}{(x+m)^{\varphi}}
$$

From here, the result of the integration depends on whether the value of $\varphi$ is unity, nil or any other value.

Case of the fractality index, $\varphi$, equal to 1

$$
\begin{aligned}
& \ln \frac{F(x)}{F(1)}=-k \ln \frac{x+m}{1+m} \\
& \frac{F(x)}{F(1)}=\frac{(1+m)^{k}}{(x+m)^{k}} \\
& F(x)=\frac{F(1)(1+m)^{k}}{(x+m)^{k}}
\end{aligned}
$$

From Eq. 14, considering different values of $x, k$ and $m$, we deduce the following bibliometric equations:

Deduction of Zipf's Law, Mandelbrot's Law, Leimkuhler's Generalized Law, and Lotka-Pareto's Law.

$$
\varphi=1, x=r, k \neq 1, m \neq 0 \Rightarrow F(r)=\frac{k_{m}}{(r+m)^{\alpha}}
$$

where $K_{m}$ is the Mandelbrot Constant.

$$
k_{m}=F(1)(1+m)^{k}
$$


and $\alpha$ is the Booth and Federowicz exponent. It represents the inverse of the HausdorffBesicovitch dimension or the fractal dimension, $D$.

$$
\alpha=k=\frac{1}{D}
$$

This is the expression that Mandelbrot deduced from lexicographic trees and these constitute the basis of Fractal Theory. On the other hand, here the deduction is made in another way. In conclusion, Fractal Theory is a particular case of the Unified Scientometric Model.

Bradford's Law is nothing more than the definite integral of Zipf's Law. Therefore, integrating each of the different equations assigned to Zipf's Law, we get all the equations assigned to Bradford's Law.

$$
R(r)=\int_{0}^{r} F(r) d r
$$

where $R(r)$ is the accumulated quality of the actor $F$. In the case of productivity of journals, $R(r)$ represents the number of articles accumulated.

In specific, Zipf-Mandelbrot's Law, which has been deduced, lead to Leimkuhler's Generalized Law applying Eq. 18. Thus:

$$
\begin{aligned}
& R(r)=\int_{0}^{r} \frac{k_{m}}{(r+m)^{\alpha}} d r \\
& R(r)=\frac{k}{1-\alpha}(r+m)^{1-\alpha}+m^{1-\alpha}
\end{aligned}
$$

Eq.20 has the same structure as that found by Rousseau. ${ }^{25}$ Nevertheless, it would be worthwhile, when appropriate, to make a more detailed study to identify exactly all the constants.

Lotka's Law is arrived at, as the derivate, with the sign changed, from the inverse function of Zipf's Law:

$$
A(F(r))=-\frac{d r}{d F(r)}
$$

where $A(F(r))$ is the number of actors for which the quality equals $F(r)$. Normally, $A(F(r))$ is similar to the number of authors or researchers who publish $F(r)$ works. Nevertheless, it can be associated with other types of production (GNP, sales, purchases, salary, etc.) and with other actors (countries, companies, customers, workers, etc.). In these cases, it is usually called Pareto's Law, but formally it is identical with Lotka's Law. 
The inverse of Mandelbrot's Law is:

$$
r=\left(\frac{k_{m}}{F(r)}\right)^{\frac{1}{\alpha}}-m
$$

Making the replacement in Eq.21, we get:

$$
A(F(r))=\frac{\frac{k_{m}^{\frac{1}{\alpha}}}{\alpha}}{F(r)^{1+\frac{1}{\alpha}}}
$$

If $R=F(r)$ and constants are regrouped, Lotka-Pareto's Law results:

$$
A(R)=\frac{A(1)}{R^{\gamma}}
$$

with

$$
A(1)=\frac{k_{m}^{\frac{1}{\alpha}}}{\alpha}
$$

and

$$
\gamma=1+\frac{1}{\alpha}
$$

Deduction of the Booth-Federowicz Law and Lotka's Law

$$
\varphi=1, x=r, k \neq 1, m=0 \Rightarrow F(r)=\frac{k_{b}}{r^{\alpha}}
$$

where $k_{b}$ is the Booth and Federowicz constant.

$$
k_{b}=F(1)
$$

In this case, $F(1)$ is situated over the centre of the translation space.

Bradford's Law is determined in a way similar to the procedure followed in the foregoing section, by integration of Zipf's Law:

$$
R(r)=\int_{0}^{r} \frac{F(1)}{r^{k}} d r
$$




$$
R(r)=\frac{F(1)}{(1-k) r^{k-1}}
$$

This expression has no equivalent in the literature available and appears not to have described before. In this sense, the model proposed presents predictive capacity of laws heretofore undescribed.

This expression of Zipf's Law also leads to Lotka's Law, as occurred with Mandelbrot's Law, with an identical result.

Deduction of the Brookes-Zipf Law, Leimkuhler's Law, and Lotka's Law.

$$
\varphi=1, x=r, k=1, m \neq 0 \Rightarrow F(r)=\frac{k_{b r}}{m+r}
$$

where $k_{b r}$ is the Brookes constant.

$$
k_{b r}=F(1)(1+m)
$$

The Brookes-Zipf Law is deduced when the dimension of the translation space is equal to unity: the actors are distributed along a completely straight line of ranges.

From this expression, it is possible to deduce Leimkuhler's Law, since replacing Eq. 31 with Eq. 19 and integrating gives:

$$
R(r)=k_{b r} \ln \left(1+\frac{r}{m}\right)
$$

which is identical to that of Leimkuhler, with $a=k_{b r}$ and $b=1 / m$

Similarly, Lotka's Law resulting from the replacement in Eq. 21 is the expression with the exponent equal to 2 .

$$
A(R)=\frac{A(1)}{R^{2}}
$$

\section{Deduction of the Condon-Zipf Law}

This is the initial expression of Zipf's Law (previously described by Condon). It is the simplest case, in which the centre of the translation space coincides with the actor of greatest frequency, and the fractal dimension is unity: the actors are arranged on a straight line.

$$
\varphi=1, x=r, k=1, m=0 \Rightarrow F(r)=\frac{F(1)}{r}
$$


After integrating from a range $r_{0}$ to $r$, the resulting Bradford's Law is the one that fits the straight fraction (Brookes-Ferreiro Equation):

$$
\begin{aligned}
& R(r)=\int_{r_{0}}^{r} \frac{F(1)}{r} d r \\
& R(r)=a \log r+c
\end{aligned}
$$

where $\mathrm{a}=F(1) / 2.303$ and $c=F(1) \ln r_{0}$.

In the same way as in the preceding section, Lotka's Law deduced is the expression with the exponent equal to 2 :

$$
A(R)=\frac{A(1)}{R^{2}}
$$

Case of the fractality index, $\varphi$, equal to 0

Eq. 11 is transformed into the following:

$$
\int_{F(1)}^{F(x)} \frac{d F(x)}{F(x)}=-k \int_{1}^{x} d x
$$

for which the solution is:

$$
\begin{aligned}
& \ln \frac{F(x)}{F(1)}=-k x+k \\
& F(x)=F(1) e^{k} e^{-k x} \\
& F(x)=F(0) e^{-k x}
\end{aligned}
$$

where:

$$
F(0)=F(1) e^{k}
$$

Meaning of the fractality index, $\varphi$

The fractal model developed by Mandelbrot is applied not only to Zipf's Law of word distribution but also to a multitude of social and natural phenomena, such as fluctuations in the stock market, population distribution, wealth distribution, plant development, Brownian movement, crystal growth, surface of catalysers, and a long list 
of etceteras. In all cases, the function found is of inverse-power or Zipf (or LotkaPareto, which is equivalent) type.

On the other hand, it can be seen that Eq. 42, which was obtained when the parameter $\varphi=0$, is exponential and not of the inverse power Zipf type, like all the previous ones when $\varphi=1$. This indicates that when $\varphi=1$, the system is fractal (because it obeys Zipf's Law and is represented by a inverse-power equation) whereas when $\varphi=0$, the system must have a structure other than fractal, at least according to Mandelbrot's model, as the function is not inverse power, but rather exponential.

In the cases in which $\varphi$ presents an value between zero and unity, the translation space considered should present a hybrid or semifractal structure. In these hybrid cases, the functions that result are intermediate between exponential and inverse power.

There is a fourth case in which $\varphi<0$. The function obtained is again hybrid, between exponential and power. The scheme is therefore symmetrical, where $\varphi=0$ makes a boundary between more or less fractal cases and more or less transfractal. The term transfractal was chosen because it means "beyond fractality", implying the crossing of a dividing line or boundary between the two zones.

All this induces us to establish a fractality scale by using the value $\varphi$, and therefore from the start we have called it the fractality index (Table 1).

Table 1. Fractality index and type of translation space

\begin{tabular}{ccc}
\hline Fractality index, $\varphi$ & Type of translation space & Type of model \\
\hline 1 & Fractal & Inverse power \\
$0<\varphi<1$ & Semifractal & Exponential - Power \\
0 & Boundary & Exponential \\
$<0$ & Transfractal & Exponential - Power \\
\hline
\end{tabular}

In addition, the co-fractality index, $\beta$, is defined as $\beta=1-\varphi$, the meaning of which is complementary to that of the fractality index.

\section{Deduction of Brookes' Law of the Ageing of Science}

Here, the coordinate $x$ is age, $t$, of the citations or of the references. Let us consider a very simplified model that implies that as time passes, inevitably, the documents and volumes of the journals gradually lose the citations from a high rate during the year at age zero to disappearance at infinity (Brookes Model). Below, we shall develop our own new model which can fully explain the behaviour of the citation, both synchronic as well as diachronic, which includes the effect of delays in publications as well as the possibility that a residual utility period persists even after an enormously long period of time. On the other hand, in the simplest case, the Brookes model, we find that:

$$
\text { For } \varphi=0, x=t, k>0 \Rightarrow F(t)=F(0) e^{-k t}
$$


This exponential function is decreasing since $k$ is considered positive. If the citations or the references are proportional to the number of documents $F(t)$ and we denote them by $c(t)$, Eq. 44 becomes:

$$
c(t)=c(0) e^{-k t}
$$

The utility of a set of documents subject to citation, $U(t)$, is considered to be the total of citations that it can receive from the present, or any time, $t$, until the end of its life. Therefore, on integrating from age $t$ to infinity, the resulting utility $U(t)$ is:

$$
\begin{aligned}
& U(t)=\int_{t}^{\infty} c(t) d t \\
& U(t)=\int_{t}^{\infty} c(0) e^{-k t} d t \\
& U(t)=c(0) k e^{-k t}
\end{aligned}
$$

If

$$
\begin{aligned}
& U(0)=c(0) k \\
& a=e^{-k} \quad 0 \leq a \leq 1
\end{aligned}
$$

we get

$$
U(t)=U(0) a^{t}
$$

which is the fundamental equation of the Brookes' model of Utility or Ageing of Science.

Since $k=1 / D$, the annual ageing factor, $a$, and the dimension of the translation space, $D$, are related. From Eq. 50, it can be deduced that:

$$
a=e^{-\frac{1}{D}}
$$

Taking into account that the half-life, $h$, of the citations or of the references is the time in which the utility is reduced to half, $U(h)=U(0) / 2$, we can easily deduce from Eq. 51 that:

$$
h=\frac{\ln \left(\frac{1}{2}\right)}{\ln a}
$$


Combining this expression with Eq. 52, we deduce that the half-life of the citations or of the references is related to the dimension of the translation space, in such a way that the quotient between the two is constant:

$$
\frac{h}{D}=\ln 2
$$

A reduction in dimension is associated with a slowing of the ageing factor, with a decrease in the half-life, and therefore with a greater degree of ageing. It could be interpreted that the existence of many degrees of freedom (large $D$ ) helps a document maintains its utility, while the few of degrees of freedom lead inevitably to obsolescence. In Table 2, some values have been calculated as an example.

\begin{tabular}{cccc}
\multicolumn{5}{c}{ Table 2. Dimension of the translation space and aging of Science } \\
\hline Dimension, $D$ & Ageing factor, $a$ & Half-life, h (years) & Ageing \\
\hline Infinity & 1.00 & Infinity & Null \\
20 & 0.95 & 13.9 & Low \\
10 & 0.90 & 6.9 & Moderate \\
5 & 0.82 & 3.5 & High \\
2 & 0.61 & 1.4 & Highest \\
\hline
\end{tabular}

The table reveals that the dimensions of the Hausdorff-Besicovitch translation space for ageing are very large, this being quite surprising compared to what might be expected. If it was already difficult to understand fractionary dimensions or dimensions greater than three in geometric spaces, it appears to be even harder to grasp the idea of temporal space of 10,20 or more dimensions. We will not dwell further on this question in the present work, but it will doubtless be a compelling challenge for future exploration.

\section{Deduction of Price's Law of Exponential Growth of Science}

The foregoing case differs only in that $k$ is now negative and thus the exponential becomes positive.

$$
\varphi=0, x=t, k<0 \Rightarrow F(t)=F(0) \mathrm{e}^{-k t}
$$

If we use $P(t)$ to denote the production of articles, the population of researchers, the number of journals or any other variable related with the size of Science, and, furthermore, make the change $k^{\prime}=k$, Eq. 44 transforms into the well-known Price equation:

$$
P(t)=P(0) e^{k^{\prime} t}
$$


This is the case in which the translation spaces can be considered semi-fractal or transfractal. Equation 11 must be directly integrated:

$$
\begin{aligned}
& \int_{F(1)}^{F(x)} \frac{d F(x)}{F(x)}=-k \int_{1}^{x} \frac{d x}{(x+m)^{\varphi}} \\
& \ln \frac{F(x)}{F(1)}=-\frac{k}{1-\varphi}(x+m)^{1-\varphi}+\frac{k}{1-\varphi}(1+m)^{1-\varphi} \\
& F(x)=F(1) e^{\frac{k}{1-\varphi}(1+m)^{1-\varphi}} e^{\frac{-k}{1-\varphi}(x+m)^{1-\varphi}}
\end{aligned}
$$

If we define

$$
\begin{aligned}
& F(0)=F(1) e^{\frac{k}{1-\varphi}(1+m)^{1-\varphi}} \\
& b=\frac{k}{1-\varphi}
\end{aligned}
$$

and

$$
\beta=1-\varphi
$$

then the general equation of the model, applicable for any value of $\varphi$, except for the unity that represents Zipf-type or purely fractal expression (Eq. 15), is:

$$
F(x)=F(0) e^{-b(x+m)^{\beta}}
$$

This expression represents what we shall hereafter call Zipf's Unified Law. As in previous sections, we can deduce expressions for Lotka's Unified Law and Bradford's Unified Law.

Deduction of Lotka's Unified Law.

If we use $T=F(x)$ and $T_{0}=F(0)$ to denote Zipf's Unified Law (Eq. 62), it has the following aspect:

$$
T=T_{0} e^{-b(x+m)^{\beta}}
$$

The inverse function is determined by solving $x$ as a function of $T$, giving: 
R. BAILÓN-MORENO et al.: The Unified Scientometric Model

$$
x=\left[-\frac{1}{b} \ln \left(\frac{T}{T_{0}}\right)\right]^{\frac{1}{\beta}}-m
$$

By definition, Lotka's Law is the derivate of the inverse function of Zipf's Law with the sign changed:

$$
A(T)=-\frac{d x}{d T}
$$

Combining this expression with Eq. 64, we get the following result:

$$
\begin{aligned}
& A(T)=\frac{\left[-\frac{1}{b} \ln \left(\frac{T}{T_{0}}\right)\right]^{\frac{1}{\beta}-1}}{b \beta T} \\
& A(T)=\frac{\left(\frac{-1}{b}\right)^{\frac{1-\beta}{\beta}}}{b \beta} \frac{\left.\ln \left(\frac{T}{T_{0}}\right)\right]^{\frac{1-\beta}{\beta}}}{T}
\end{aligned}
$$

if

$$
\begin{aligned}
& B=\frac{\left(\frac{-1}{b}\right)^{\frac{1-\beta}{\beta}}}{b \beta} \\
& A(T)=\frac{B}{T\left[\ln T-\ln T_{0}\right]^{\frac{\beta}{1-\beta}}}
\end{aligned}
$$

if, furthermore,

$$
\begin{aligned}
& \lambda=\ln T_{0} \\
& \mu=\frac{\beta}{1-\beta}
\end{aligned}
$$

For Lotka's Unified Law the resultant is the following:

$$
A(T)=\frac{B}{T(\ln T-\lambda)^{\mu}}
$$


As opposed to the classical Lotka's Law, in which the number of actors $A(T)$ that have produced $T$ items (using the nomenclature of the IPP of Egghe and Rousseau) are in an inverse power relationship, Lotka's Unified Law, which has been deduced, shows that the number of actors is inversely proportional to the $T$ items and to a power of the logarithm of these $T$ items.

Deduction of Bradford's Unified Law. Bradford's Law Unified will be, using arguments identical to those in previous sections, the following expression:

$$
\begin{aligned}
& R(r)=\int_{x_{0}}^{x} F(x) d x \\
& R(r)=\int_{x}^{x} F(0) e^{-b(x+m)^{\beta}} d x
\end{aligned}
$$

The analytical resolution of this integral is very complex, and thus in practice only numerical solutions are possible. The trapezoid rule or Simpson's rule can be used to indicate two common methods.

\section{The Unified Scientometric Model for Complex Translations}

According to the Fifth Principle or the Principle of the Composition of Translations, any translation, regardless of how complex, can be interpreted as a composition of elemental translations in a series, in parallel or in a combination of the two forms.

As an example of this possibility, a very general and novel Ageing-Viability Model will be developed, which, as in particular cases, leads to Avramescu's and Brookes' equations.

\section{Generalized Model of Ageing -Viability}

Let us consider a set of recently published documents subject to be cited. Let us structure this set in four possible states (each state can be considered a different actor as its definition is also different). The states or actors are:

State $X$ : Documents with low translation capacity and therefore will never be cited.

State $P$ : Documents with a sufficiently high translation capacity to influence later works but, for the delay in the publication of the later works, the former must wait to be cited.

State $C$ : Documents that are currently being cited. In the future these could maintain this state, but the trend will be translated to state $N$. 
State $N$ : Documents that have been cited at some time but that currently have declined in viability. Nevertheless, there is a certain probability to be translated again to the citation state, $C$, but this probability will progressively diminish with time.

The translation from state $P$ to $C$ is irreversible, since once reached (to be cited once) it is not possible to go back. On the other hand, between states $C$ and $N$, a dynamic equilibrium between viability (state $C$ ) and obsolescence (state $N$ ) is established, this with time being tipped towards ageing. Nevertheless, it is expected that the final equilibrium does not lead to the total and absolute disappearance of viability; rather a residual viability remains regardless of the passage of time. It is known that practically no document is cited after 20 to 30 years, but certain ones nevertheless maintain a certain degree of citation. Some persist decades and even centuries. It is evident that works such as Philosophiae Naturalis Principia Mathematica of Isaac Newton, The Book of the Dead of Egypt, the Code of Hammurabi, or the Bible, to cite a few notable examples, will always have a place in the reference lists of later documents.

The model described corresponds to the following combination of elemental translations:

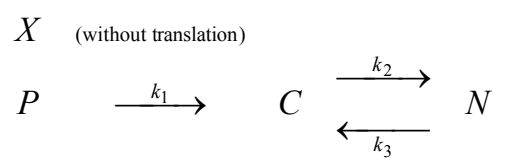

The three translations of the system are:

1. First citation and acquisition of "viability" quality (translation from $P$ to $C$ )

2. Obsolescence or Ageing (translation from $C$ to $N$ )

3. Recovery of viability (translation from $N$ to $C$ )

The fundamental equation of the Unified Scientometric Model for each elemental process of translation, $i$, is the following:

$$
T_{i}=k_{i} s q
$$

The complex translation applied to an actor, $j$, is the sum of the elemental translations that affect it, but taking into account that, if the elemental translation implies increased quality, the strategic advantage is defined as constant and equal to +1 $(s=+1)$. If the elemental translation involves, on the other hand, reduced quality, the strategic advantage is equal to $-1(s=-1)$ Consequently, translations that each of the actors (or states) undergoes are:

$$
\begin{array}{ll}
\text { Type - } P \text { Actors : } & \frac{d p}{d t}=-k_{1} p \\
\text { Type- } C \text { Actors : } & \frac{d c}{d t}=k_{1} p-k_{2} c+k_{3} n
\end{array}
$$




$$
\text { Type - } N \text { Actors : } \quad \frac{d n}{d t}=k_{2} c-k_{3} n
$$

The symbols $p, c$ and $n$ indicate the number of documents (intrinsic advantage, $q$ ) in the states $P, C$ and $N$, respectively. It should be indicated that the number of citations, $C$ (in upper case) at a given moment is proportional to the number of documents that at that moment are being cited, $c$ (lower case):

$$
C=\lambda c
$$

where: $\lambda$ is the density of the mean citation (Citations / Article) (constant over the time period studied).

Note that the rate at which the $P$-type actors undergo a qualitative loss $(s=-1)$ is proportion to their qualitative level at each instant. On the other hand, $C$-type actors are affected by the three elemental translations simultaneously. That is, they increase their quality "to be cited", thanks to the translation "acquisition of viability" from $P$ to $C$ $\left(+k_{1} P\right.$, since $s=+1$ and $q=P$ ) and to the translation "recovery of viability" from $N$ to $C$ $\left(+k_{3} N\right.$, since $=+1$ and $\left.q=N\right)$ and to the translation "ageing", for the passage from $C$ to $N\left(-k_{2} C\right.$, with $s=-1$ and $\left.q=C\right)$. Analogously, the $N$-type actors are translated positively thanks to the passage of $C$ to $N$ and negatively by the passage of $N$ to $C$.

The integration of Eq. 77 leads to the following expression:

$$
p=p_{0} e^{-k_{1} t}
$$

If we replace this equation in the system formed by Eq. 78 and Eq. 79, previously rearranged, we get:

$$
\begin{gathered}
D c+k_{2} c-k_{3} n=k_{1} p_{0} e^{-k_{1} t} \\
D n-k_{2} c+k_{3} n=0
\end{gathered}
$$

where $D$ is the operator derivate:

$$
D \equiv \frac{d}{d t}
$$

Finding the common factor in both equations, we get:

$$
\begin{gathered}
\left(D+k_{2}\right) c-k_{3} n=k_{1} p_{0} e^{-k_{1} t} \\
\left(D+k_{3}\right) n-k_{2} c=0
\end{gathered}
$$

If the first is multiplied by $\left(D+k_{3}\right)$ and the second by $k_{3}$, and the resulting equations are added together, we get the following expression, the function that depends only on the number of documents, $c$, which are being cited at the instant or age $t$ :

$$
\left(D+k_{2}\right)\left(D+k_{3}\right) c-k_{2} k_{3} c=\left(D+k_{3}\right) k_{1} p_{0} e^{-k_{1} t}
$$


Performing the appropriate operations, we get:

$$
D^{2} c+\left(k_{2}+k_{3}\right) D c=\left(k_{1} k_{3}-1\right) p_{0} e^{-k_{1} t}
$$

which is a second-order differential equation of which the characteristic equation, without the second member, is equal to:

$$
D^{2}+\left(k_{2}+k_{3}\right) D=0
$$

for which the solutions or roots are:

$$
\begin{gathered}
r_{1}=0 \\
r_{2}=-\left(k_{2}+k_{3}\right)
\end{gathered}
$$

The general solution, without considering the second member, is then:

$$
c=a_{1}+a_{2} e^{-\left(k_{2}+k_{3}\right) t}
$$

Given that the second member is exponential, the particular solution is also exponential of the type:

$$
f(t)=a_{3} e^{-k_{1} t}
$$

This equation should satisfy the complete differential equation (Eq. 86), such as:

$$
\begin{aligned}
& f^{\prime}(t)=-a_{3} k_{1} e^{-k_{1} t} \\
& f^{\prime \prime}(t)=a_{3} k_{1}^{2} e^{-k_{1} t}
\end{aligned}
$$

Carrying out replacements in Eq. 86 and the appropriate calculations, the value of $a_{3}$ is determined:

$$
a_{3}=\frac{k_{3}-1}{k_{1}-\left(k_{2}+k_{3}\right)}
$$

which is replaceable in the complete general equation:

$$
c=a_{1}+a_{2} e^{-\left(k_{1}+k_{2}\right) t}+a_{3} e^{-k_{1} t}
$$

Also, when:

$$
t \rightarrow \infty \Leftrightarrow a_{1}=c_{\infty}
$$

where $a_{1}$ is the number of documents that are residually cited at the infinite age.

If we take into account that the number of citations or references is proportional to the number of documents in the state of citation (Eq. 80), the resulting Equation of the Ageing-Viability Model is: 


$$
C=A_{1}+A_{2} e^{-\left(k_{2}+k_{3}\right) t}+A_{3} e^{-k_{1} t}
$$

with:

$$
\begin{aligned}
& A_{1}=\lambda a_{1}=\lambda c_{\infty} \\
& A_{2}=\lambda a_{2} \\
& A_{3}=\lambda a_{3}=\lambda \frac{k_{3}-1}{k_{1}-k_{2}-k_{3}}
\end{aligned}
$$

Deduction of Avramescu's Equation. Admitting that the degree of the residual citation at infinity is nil, $A_{1}=0$ and $k_{3}=0$ (since there is no translation to go from $N$ to $C$, or else $k_{3}$ is proportionally very small with respect to $k_{2}$ ). Thus:

$$
C=A_{2} e^{-k_{2} t}+A_{3} e^{-k_{1} t}
$$

Furthermore, if no citations occur in the year zero:

$$
0=A_{2}+A_{3}
$$

and therefore:

$$
C=A_{2}\left(e^{-k_{2} t}-e^{-k_{1} t}\right)
$$

This is Avramescu's Equation.

Deduction of Brookes' Equation. If we consider that there is no delay in the citation process $\left(k_{1}\right.$ is very large) Avramescu's Equation transforms into:

$$
C=A_{2} e^{-k_{2} t}
$$

This identical to:

$$
c(t)=c(0) e^{-k t}
$$

which, by integration, as before, generates Brookes' utility equation:

$$
U(t)=U(0) a^{t}
$$

\section{Summary of the Scientometric Laws unified by the model}

Table 3 presents a summary of the scientometric laws that have been deduced with the Unified Scientometric Model proposed here. 
R. BAILÓN-MORENO et al.: The Unified Scientometric Model

Table 3. Laws that the model unifies

\begin{tabular}{|c|c|c|c|c|c|}
\hline$\varphi$ & $x$ & $K$ & $m$ & Distribution & Equation \\
\hline \multirow{12}{*}{$\begin{array}{c}1 \\
\text { Fractal }\end{array}$} & \multirow{12}{*}{$\begin{array}{c}r \\
\text { Ranks }\end{array}$} & \multirow{6}{*}{$\neq 1$} & \multirow{3}{*}{$\neq 0$} & Zipf - Mandelbrot & $F(R)=\frac{k_{m}}{(r+m)^{\alpha}}$ \\
\hline & & & & Lotka $\varphi \neq 2$ & $A(R)=\frac{A(1)}{R^{\gamma}}$ \\
\hline & & & & Generalized Leimkuhler & $R(r)=\frac{k}{1-\alpha}(r+m)^{1-\alpha}+m^{1-\alpha}$ \\
\hline & & & \multirow{3}{*}{0} & Booth - Federowicz & $F(R)=\frac{k_{b}}{r^{\alpha}}$ \\
\hline & & & & Lotka $\varphi \neq 2$ & $A(R)=\frac{A(1)}{R^{\gamma}}$ \\
\hline & & & & $\begin{array}{c}\text { Bradford } \\
\text { (Not described } \\
\text { in bibliography) }\end{array}$ & $R(r)=\frac{F(1)}{(1-k) r^{k-1}}$ \\
\hline & & \multirow{6}{*}{1} & \multirow{3}{*}{$\neq 0$} & Zipf - Brookes & $F(R)=\frac{k_{b r}}{r+m}$ \\
\hline & & & & Lotka $\varphi=2$ & $A(R)=\frac{A(1)}{R^{2}}$ \\
\hline & & & & Leimkuhler & $R(r)=k_{b r} \ln \left(1+\frac{r}{m}\right)$ \\
\hline & & & \multirow{3}{*}{0} & Condon - Zipf & $F(R)=\frac{k_{m}}{r}$ \\
\hline & & & & Lotka $\varphi=2$ & $A(R)=\frac{A(1)}{R^{2}}$ \\
\hline & & & & Brookes - Ferreiro & $R(r)=a \log r+c$ \\
\hline
\end{tabular}


Table 3. (continued)

\begin{tabular}{|c|c|c|c|c|c|}
\hline$\varphi$ & $x$ & $K$ & $m$ & Distribution & Equation \\
\hline \multirow[b]{2}{*}{$\begin{array}{c}0 \\
\text { Boundary }\end{array}$} & \multirow{4}{*}{$\begin{array}{l}\mathrm{t} \\
\text { Time } \\
\text { or } \\
\text { Age }\end{array}$} & $>0$ & - & $\begin{array}{c}\text { Brookes' Law of } \\
\text { the Ageing of } \\
\text { Science }\end{array}$ & $U(t)=U(0) a^{t}$ \\
\hline & & $<0$ & - & $\begin{array}{c}\text { Price's Law of } \\
\text { Exponential } \\
\text { Growth of } \\
\text { Science }\end{array}$ & $P(t)=P(0) e^{k^{\prime} t}$ \\
\hline \multirow{2}{*}{$\begin{array}{c}\varphi \\
\text { not defined. } \\
\text { Complex } \\
\text { translation }\end{array}$} & & $\begin{array}{l}K_{1} \\
K_{2} \\
K_{3}\end{array}$ & - & $\begin{array}{l}\text { Generalizad Model } \\
\text { of Ageing-Viability }\end{array}$ & $C=A_{1}+A_{2} e^{-\left(k_{2}+k_{3}\right) t}+A_{3} e^{-k_{1} t}$ \\
\hline & & $\begin{array}{l}K_{1} \\
K_{2}\end{array}$ & & $\begin{array}{l}\text { Avramescu's } \\
\text { Equation }\end{array}$ & $C=A_{2}\left(e^{-\left(k_{2}+k_{3}\right) t}-e^{-k_{1} t}\right)$ \\
\hline \multirow{3}{*}{$\begin{array}{l}\varphi \neq 1 \\
\varphi \neq 0 \\
\text { Unified }\end{array}$} & \multirow{3}{*}{$\mathrm{r}, \mathrm{t}$} & \multirow{3}{*}{$\mathfrak{R}$} & \multirow{3}{*}{$\geq 0$} & $\begin{array}{l}\text { Zipf's Unified } \\
\text { Law }\end{array}$ & $F(x)=F(0) e^{-b(x+m)^{\beta}}$ \\
\hline & & & & $\begin{array}{l}\text { Lotka's Unified } \\
\text { Law }\end{array}$ & $A(T)=\frac{B}{T(\ln T-\lambda)^{\mu}}$ \\
\hline & & & & $\begin{array}{l}\text { Bradford's Unified } \\
\text { Law }\end{array}$ & $R(x)=\int_{x_{0}} F(x) d x$ \\
\hline
\end{tabular}

\section{Conclusions}

The Unified Scientometric Model presented in this work represents the quantification of the Actor-Network Theory and Translation Theory, as well as their integration with the Fractal and Accumulated-Advantages Models. Similarly, it expands the Fractal Model paradigm through the concepts of the Index of Fractality and Transfractality.

In an introductory display of its potential, it has proven capable of unifying all the bibliometric laws known: Zipf's Law in its various forms (Condon-Zipf, BoothFederowicz, Brookes-Zipf and Zipf-Mandelbrot), Bradford's Law and analogous forms (Brookes-Bradford Equation, Leimkuhler's Equation, Leimkuhler's Generalized Equation), Lotka's Law and Pareto's Law, Price's Law of the growth of science, and the ageing Laws of Brookes and Avramescu. In addition, we propose other laws not described in the literature, particularly the unified laws of Zipf, Bradford and Lotka.

Future works will show that the model proposed is capable even of explaining simultaneously the Mateo Effect, the advantage of the "elite", the Ortega hypothesis, and the advantage of the "mediocre". Furthermore, it will be shown that it is an effective tool for making predictions, thanks to an innovative combination of relational indicators of activity. 
This study was supported by the Spanish Ministry of Science and Technology through projects no. 1FD97-0931 and PB1998-1293.

\section{References}

1. BAILÓN-MORENO, R. Ingeniería del conocimiento y vigilancia tecnológica aplicada a la investigación en el campo de los tensioactivos. Desarrollo de un modelo ciencimétrico unificado. Ph. D. Thesis. Universidad de Granada, Granada, 2003.

2. Brookes, B. C., Towards informetrics: Haitun, Laplace, Zipf, Bradford and the ALVEY programme. Journal of Documentation, 40 (1984) 120-143.

3. Condon, E. U., Statistics of vocabulary. Science, 68 (1928) 1733.

4. ZIPF, G. K., Human Behaviour and the Principle of Least Effort, Adisson-Wesley Press, Inc, Cambridge, 1949.

5. MANDELBROT, B. B., An informational theory of the stadistical structure of language. In: W. JACKSON (Ed.), Communication Theory, pp. 486-502. London, Butterworths Scientific Publications, 1953.

6. Federowicz, J. E., A zipfian model on automatic bibliographic system: an application to MEDLINE. Journal of the American Society for Information Science, 33 (1982) 223-232.

7. Federowicz, J. E., The theorical foundation of Zipf's law and its application to the bibliographic database environment. Journal of the American Society for Information Science, 33 (1982) 285-293.

8. Mandelbrot, B. B., The Fractal Geometry of Nature, Freeman, New York, 1977.

9. Mandelbrot, B. B., Structure formelle des textes et communication (deux études). Word, 11 (1954) 424.

10. RousSEAU, R., The nuclear zone of a Leimkuhler curve. Journal of Documentation, 43 (1987) 322-333.

11. Burrell, Q. L., Modelling the Bradford phenomenon. Journal of Documentation, 44 (1988) 1-18.

12. Brookes, B. C., The Bradford law: a new calculus for the social sciences? Journal of the American Society for Information Science, 30 (1979) 233-234.

13. LEIMKUHLER, F. F., An exact formulation of Bradford's law. Journal of Documentation, 36 (1980) 285-292.

14. BRoOKES, B. C., A critical commentary on Leimkuhler's 'exact' formulation of the Bradford law. Journal of Documentation, 37 (1981) 77-88.

15. BROOKES, B. C., The empirical law of natural categorization. Journal of Information Science, 6 (1983) $147-157$.

16. BRADFORD, S. C., Sources of information on specific subjects. Journal of Information Science, 10 (1985) 173-180.

17. BRADFORD, S. C., Sources of informations on specific subjects. Engineering, 137 (1934) 85-86.

18. Brookes, B. C., Bradford's law and the bibliography of science. Nature, 224 (1969) 653-656.

19. Ferreiro-Alaez L., Mendez A., Linealidad de las dispersiones Bradford. Revista Española de Documentación Cientifica, 3 (1980) 201-211.

20. LeIMKUHLer, F. F., The Bradford distribution. Journal of Documentation, 23 (1967) 197-207.

21. Groos, O. V., Bradford's law and the Keenan-Atherton data. American Documentation, 18 (1967) 46.

22. BROOKES, B. C., "Source of information on especific subjects" by S.C. Bradford. Journal of Information Science, 10 (1985) 173-180.

23. PRICE, D. J. DE S., A general theory of bibliometric and other cumulative advantage processes. Journal of the American Society for Information Science, 27 (1976) 292-306.

24. Rousseau, R., The number of authors per article in library and information science can often be described by a simple probability distribution. Journal of Documentation, 50 (1994) 134-141.

25. RousseAu, R., Lotka's law and its Leimkuhler representation. Library Science with a Slant to Documentation and Information Studies, 25 (1988) 150-178. 
26. EGGHE, L., Consequences of Lotka's law for the law of Bradford. Journal of Documentation, 41 (1985) $173-189$.

27. LoPeZ-Piñero, J. M., Price, D. J. DE Solla, Hacia una ciencia de la ciencia. Barcelona, Ariel, 1973.

28. LotkA, A. J., The frequency distribution of scientific productivity. Journal of the Washington Academy of Science, 16 (1926) 317-323.

29. PAO, M. L., Lotka's law: a testing procedure. Information Processing \& Management, 21 (1985) 305-320.

30. Sutter, M., Kocher, M. G., Power laws of research output. Evidence for journals of economics. Scientometrics, 51 (2001) 405-414.

31. CHen, Y., Analysis of Lotka's Law: The Simon-Yule Approach. Information Processing \& Management, 25 (1989) 527-544.

32. PrICE, D. J. DE S., Little Science, Big Science, Columbia Univ. Pt., New York, 1963.

33. EGGHE, L., RAO, I. K. R., Classification of growth models based on growth rates and its applications. Scientometrics, 25 (1992) 5-46.

34. EGGHE, L., On the influence of growth on obsolescence. Scientometrics, 27 (1993) 195-214.

35. TAgue, J., Beheshti, J., ReEs-PotTer, L., The law of exponential growth: evidence, implications and forecasts. Library Trends, 30 (1981) 125-149.

36. BROOKES, B. C., Obsolescence of special library periodicals: sampling errors and utility contours. Journal of the American Society for Information Science, 21 (1970) 320-329.

37. Griffith, B. C., Servi, P. N., ANKER, A. L., DrotT, M. C., The aging of scientfic literature: a citation analysis. Journal of Documentation, 35 (1979) 179-196

38. GAPEN, D. K., Milner, S. P., Obsolescence. Library Trends, 30 (1981) 107-124.

39. Wallace, D. P., The relationship between journal productivity and obsolescence. Journal of the American Society for Information Science, 37 (1986) 136-145.

40. EgGHe, L., RAO, I. K. R., Citation age data and the obsolecence funtion: fits and explanations. Information Processing \& Management, 28 (1992) 201-217.

41. Diodato, V., Smith, F., Obsolescence of music literature. Journal of the American Society for Information Science, 44 (1993) 101-112.

42. Burton, R. E., Kebler, R. W., The "half-life" of some scientific and technical literatures. American Documentation, 11 (1960) 18-22.

43. EgGhe, L., RaO, I. K. R., Rousseau, R., On the influence of production on utilization functions: obsolescence or increased use? Scientometrics, 34 (1995) 285-315.

44. RUIZ-BAÑOS, R., JIMÉNEZ-CONTRERAS, E., Envejecimiento de la literatura científica en documentación. Influencia del origen nacional de las revistas. Estudio de una muestra. Revista Española de Documentación Cientifica, 19 (1996) 39-49.

45. Brookes, B. C., Optimun p\% library of scientific periodical. Nature, 232 (1971) 458-461.

46. RuIZ-BAÑOS, R., BAILÓN-MORENO, R., Métodos para medir experimentalmente el envejecimiento de la literatura científica. Boletín de la Asociación Andaluza de Bibliotecarios, 46 (1997) 57-75.

47. RUIZ-BAÑos, R., Un modelo de expurgo para las revistas científicas en bibliotecas universitarias. VIII Jornadas Bibliotecarias de Andalucia, pp. 279-288, Huelva, Diputación Provincial, 1995.

48. Avramescu, A., Actuality and obsolescence of scientific literature. Journal of the American Society for Information Science, 30 (1979) 296-303.

49. AVERSA, E. S., Citation patterns of highly cited papers and their relationship to literature aging - A study of the working literature. Scientometrics, 7 (1985) 383-389.

50. RiP, A., Courtial, J. P., Co-word maps of biotechnology: an example of cognitive scientometrics. Scientometrics, 6 (1984) 381-400.

51. Courtial, J. P., A coword analysis of scientometric. Scientometrics, 31 (1994) 251-260.

52. Callon, M., Courtial, J. P., Laville, F., Co-word analysis as a tool for describing the network of interactions between basic and technological research: the case of polymer chemistry. Scientometrics, 22 (1991) 155-205.

53. Courtial, J. P., CAhlik, T., CAllon, M., A model for social interaction between cognition and action through a key-word simulation of knowledge growth. Scientometrics, 31 (1994) 173-192. 
54. Courtial, J. P., Qualitative models, quantitative tools and network analysis. Scientometrics, 15 (1989) 527-534.

55. Callon, M., Law, J., RIP, A., Mapping the Dynamics of Science and Technology: Sociology of Science in the Real World. London, The McMillan Press LTD, 1986.

56. Callon, M., Courtial, J. P., Penan, H., Cienciometría. La medición de la actividad cientifica: De la bibliometría a la vigilancia tecnológica, Trea, Gijón, 1995.

57. CAllon, M., La science et ses réseaux: gènese et circulation des faits scientifiques. Paris, Découverte, 1989.

58. Callon, M., Representing nature, representing culture. Conference pour l'ouverture du Centre for Social Theory and Technology, 1995.

59. Courtial, J. P., Gourdon, L., A scientometric approach to autism based on translation sociology. Scientometrics, 40 (1997) 333-355.

60. Courtial, J. P., Gourdon, L., Mapping the dynamics of research on autism or the cultural logic of science. Theory and Psychology, 9 (1999) 579-604

61. Courtial, J. P., Le rôle des mots d'indexation dans la mise en évidence de la dynamique d'un domaine scientifique. Exemples de l'ethnopsychiatrie et de l'autisme. Documentaliste - Sciences de l'Information, 34 (1997) 135-141.

62. LoOze, M.-A. D., Lemarié, J., Corpus relevance through co-word analysis: an application to plant proteins. Scientometrics, 39 (1997) 267-280.

63. Noyer, J.-M., Utilisation d'outil infometrique "Candide" dans le contexte d'une réflexion stratégique: Les réseaux de simulation distribuée de l'armée des Éats-Unis-d'Amérique: émergence et description de l'émergence. Information Solaris Communication, 2 (1995), available at http://biblio-fr.info.unicaen.fr/bnum/jelec/Solaris/d02/2noyer_2.html

64. RuIZ-BAÑos, R., Ciencimetría de redes. Análisis de la investigación internacional sobre Arqueología mediante el Método de las Palabras Asociadas (1980-1993). Ph. D. Thesis. Universidad, Granada, 1997.

65. Ruiz-Baños, R., Bailón-Moreno, R., JimÉneZ-Contreras, E., Courtial, J. P., Structure and dynamics of scientific networks. Part 1: Fundamentals of the quantitative model of translation. Scientometrics, 44 (1999) 217-234.

66. Ruiz-Baños, R., Bailón-Moreno, R., Jiménez-Contreras, E., Courtial, J. P., Structure and dynamics of scientific networks. Part 2: The new Zipf's Law, the cocitations's clusters and the model of the presence of key-words. Scientometrics, 44 (1999) 235-265.

67. Ruiz-Baños, R., BAilón-Moreno, R., El método de las Palabras Asociadas (I). La estructura de las redes científicas. Boletín de la Asociación Andaluza de Bibliotecarios, 53 (diciembre) (1998) 43-60.

68. RuIZ-BAÑos, R., BAILÓN-MorenO, R., El método de las palabras asociadas (II). Los ciclos de vida de los temas de investigación. Boletín de la Asociación Andaluza de Bibliotecarios, 54 (marzo) (1999) 59-71.

69. Jurado-Alameda, E., BAilón-Moreno, R., Ruiz-BAÑos, R., Evaluación a través del Análisis de las Palabras Asociadas (I). Aplicación a la investigación científica y técnica. Ingeniería Química, 34 (2002) 141-149.

70. Jurado-Alameda, E., Bailón-Moreno, R., Ruiz-Baños, R., Evaluación a través del Análisis de las Palabras Asociadas ( y II). Evaluación de la investigación en el campo de los tensioactivos. Ingeniería Química, 34 (2002) 177-184.

71. Courtial, J. P., Introduction à la scientomètrie: de la bibliométrie à la veille techonologique, Anthropos, Paris, 1990.

72. WhitTAKER, J., Co-word analysis: The Keele programs, Universidad de Keele, UK, 1988.

73. Michelet, B., L'analyse des associations. Ph. D. Thesis. Université de Paris 7, Paris, 1988.

74. LATOUR, B., Nunca hemos sido modernos: Ensayo de antropología simétrica, Debate, Madrid, 1993.

75. Latour, B., Ciencia en acción: Cómo seguir a los científicos e ingenieros a través de la sociedad, Labor, Barcelona, 1992.

76. Latour, B., Knorr-Cetina, K., Mulkay, M. (Eds), Science Observed: Perspectives on the Social Study of Science, Sage, Londres, 1983.

77. RuIZ-BAÑos, R., Las traducciones dinámicas de las series temáticas. Propuesta de una nueva clasificación. Actas del IV Congreso ISKO España EOCONSID’99. La Representación y Organización 
del Conocimiento en sus distintas perspectivas: su influencia en la Recuperación de la Información. pp. 193-198. Capítulo Español de la Sociedad Internacional para la Organización del Conocimiento, 1999.

78. Latour, B., Woolgar, S., La vida en el laboratorio. La construcción de los hechos científicos, Alianza, Madrid, 1995.

79. SIERPINSKI, W., Sur une courbe cantorienne qui contient une image biunivoque et continue de toute courbe donné. Comptes Rendus (1916) 629.

80. Mandelbrot, B. B., Adaptation d'un message à la ligne de transmission. I \& II. Comptes Rendus, 232 (1951) 1638-1640 \& 2003-2005.

81. LORENZ, E. N., Deterministic nonperiodic flow. Journal of the Atmosferic Sciences, 20 (1963) 130-141.

82. Julia, G., Oeuvres de Gaston Julia, Gauthier-Villars, Paris, 1968.

83. VAN RAAN. A. F. J., Fractal geometry of information space as represented by co-citations clustering. Scientometrics, 20 (1990) 439-449.

84. VAn RaAn, A. F. J., Fractal dimension of co-citations. Nature, 347 (1990) 626

85. JimÉnEZ-CONTRERAS, E., Las revistas científicas: el centro y la periferia. Revista Española de Documentación Científica, 15 (1992) 174-182.

86. Hongzhou, Z., GuOHuA, J., Shifting of world's center and scientist' social ages. Scientometrics, 8 (1985) 59-80. 